\title{
The effect of precipitation on wind-profiler clear air returns
}

\author{
A. J. McDonald ${ }^{1}$, T. K. Carey-Smith ${ }^{1}$, D. A. Hooper ${ }^{2}$, G. J. Fraser ${ }^{1}$, and B. P. Lublow ${ }^{1}$ \\ ${ }^{1}$ Department of Physics and Astronomy, University of Canterbury, Christchurch, New Zealand \\ ${ }^{2}$ Rutherford Appleton Laboratory, Chilton, Didcot, Oxon, OX11 0QX, UK
}

Received: 26 August 2003 - Revised: 30 March 2004 - Accepted: 20 April 2004 - Published: 29 November 2004

Part of Special Issue "10th International Workshop on Technical and Scientific Aspects of MST Radar (MST10)"

\begin{abstract}
A small number of studies have indicated that reductions in the signal strength of clear air returns can be observed at low altitudes in regions of precipitation. This study uses data from the NERC MST radar facility in Aberystwyth $\left(52.4^{\circ} \mathrm{N}, 4.1^{\circ} \mathrm{W}\right)$ and co-located tipping bucket rain gauge data to determine whether this effect can be observed for all periods where high rainfall rates were observed at the ground. The period selected for examination includes all of the days where a peak rainfall rate of $6 \mathrm{~mm} \mathrm{~h}^{-1}$ was exceeded in 2001. A statistical examination of VHF radar signal power during periods with and without surface rainfall suggests that the returned power is reduced by the presence of precipitating clouds. The corrected spectral width of the Doppler spectra is also significantly wider during periods of precipitation. The process which causes the decrease in the VHF signal power seems to be associated with a reduction in Fresnel reflection within precipitating clouds. This, in turn, may be due to a reduction of humidity gradients in clouds. UHF wind profiler data is also used to show that there is a relationship between enhanced UHF returns (signifying precipitation) and reduced VHF returns. To clarify the processes and effects observed we examine three case studies which show typical relationships between the VHF signal power and surface rainfall or enhanced UHF signal-to-noise ratios. The effect of precipitation on the signal processing scheme's derivation of signal power and spectral width is explored using individual Doppler spectra.
\end{abstract}

Key words. Atmospheric composition and structure (instruments and techniques) - Meteorology and atmospheric dynamics (precipitation) - Radio science (remote sensing)

\section{Introduction}

Wind profiler radars operating at very high and ultra high frequencies (VHF and UHF, respectively) are sensitive to both clear air returns, from radio refractive index irregular-

Correspondence to: A. J. McDonald

(adrian.mcdonald@ canterbury.ac.nz) ities, and Rayleigh scattering, from distributed targets such as hydrometeors. The dependence of both mechanisms on wavelength means that UHF and VHF radars have very different sensitivities to these processes. A largely theoretical study described in Ralph (1995) reveals that only under conditions of heavy rain $\left(>8.4 \mathrm{~mm} \mathrm{~h}^{-1}\right)$ is the Rayleigh scattered signal expected to exceed the clear air radar return at VHF. At UHF, however, light rain or drizzle is sufficient for the Rayleigh scatter to dominate the clear air returns. These conclusions are consistent with the results described in Currier et al. (1992), which indicate that two radars that operate at $915 \mathrm{MHz}$ (UHF) and at $50 \mathrm{MHz}$ (VHF) displayed very different sensitivities to clear air and precipitation returns. Specifically, the $50 \mathrm{MHz}$ radar provided primarily clear air information, while the $915 \mathrm{MHz}$ radar provided precipitation information, with only minimal clear air information even during weak precipitation periods.

However, it should be noted that a number of studies have also indicated that VHF radar data can be used to observe precipitation echoes at lower rain rates (Wakasugi et al., 1986). In particular, Chu et al. (1991) and Rao et al. (1999) have shown that while the VHF echo power associated with precipitation is generally far weaker than that due to clear air returns, the echo power associated with precipitation is enhanced strikingly at the height of the melting layer, hence the alternative term bright band, and can be greater than that due to clear air returns by about $5 \mathrm{~dB}$. It is also interesting to note that Chu et al. (1991) reported changes in clear air return strength associated with changes in the phase of the hydrometeors. They attributed this to a cooling effect, arising from the absorption of latent heat associated with the evaporation of the raindrops. Alternatively, melting of the ice particles and a vapourizing effect due to the release of water vapour through the process of ice sublimation and raindrop evaporation was also suggested by Chu et al. (1991). Rao et al. (1999) indicated that the weakening of the clear air echo at the bright band could be due to the turbulent mixing between the warm and humid in-cloud air, and colder and drier surrounding air caused by entrainment. Fabry and Zawadzki (1995) indicate that six effects may contribute to the bright 
band: the change in the dielectric constant through the melting region; the change in fall velocity throughout the melting region; precipitation growth; the change in particle size distribution (aggregation and breakup); the combined effect on echo power of the shape and orientation of melting hydrometeors; and the effect of the distribution of the water within the melting snowflake. Their study indicates that the sum of the first three effects, which are the most cited mechanisms, account for significantly less than the total increase in power observed in the bright band.

The benefits of simultaneously observing precipitation and clear air turbulent activity using a combination of UHF and VHF radar has been recognized by the scientific community for several years. The sensitivity of these profilers to motions of hydrometeors has enabled studies of the vertical structure of precipitating clouds to be made. This vertical structure is important in understanding how the distribution of latent heating affects the atmospheric circulation and how to better parameterize precipitating clouds in numerical models. In addition, this capability has allowed many precipitation related parameters, such as the terminal velocity of hydrometeors and the three-dimensional wind-field within clouds, to be measured directly. Particular attention has been paid to accurately determining the drop size distribution of hydrometeors, which is inferred from the the spectrum of raindrop terminal fall speeds. Atlas et al. (1973) showed that a correction must be made for the vertical air velocity which offsets the whole spectrum. The accuracy of distributions derived from microwave radar observations is therefore limited by the fact that these radars are primarily sensitive to hydrometeor returns. The value of the vertical air velocity must therefore be assumed. Thus, under many conditions combined, UHF and VHF radar data is necessary to evaluate precipitation information accurately.

Chu and Song (1998) analyzed VHF radar returns from hydrometeors and refractivity fluctuations associated with a cold front. A composite analysis of the precipitation echo intensity and the vertical air velocity indicated that the latter plays a vital role in the formation of the bright band. VHF radar reflectivity from precipitation at the height around the melting layer may be enhanced for weak vertical air velocity, while the bright band may be disrupted if the upward vertical air speed is large. These updrafts may also diminish the echo intensity from refractivity fluctuations through the mechanism of turbulent mixing. They postulate that a plausible mechanism for the depletion of the precipitation echo accompanying an intense updraft in the height range of the melting layer is the process of turbulent mixing. Their study also suggests that the depletion of the clear air echo power can be attributed to the turbulent mixing between warm and humid in-cloud air, and cool and dry ambient air entrained into the cloud following a strong updraft.

Vaughan and Worthington (2000) investigated the variation in power of VHF radar vertical echoes as a function of atmospheric humidity. Their work indicated that the observed echoes are greatest in air of moderate humidity, and least in very dry or near-saturated air. The standard Fresnel scattering model for relating clear air echo power to the mean vertical gradient of generalised potential refractive index thus seems to overpredict echo power at high relative humidities (Ottersten, 1969). Their study proposes that this is due to the role of precipitation in suppressing metre-scale humidity structures. Their study also suggests that the echoes are more isotropic, and their spectra are broader, at high humidity, indicating a greater contribution from turbulent scatter than Fresnel scatter. The present study aims to examine the effects of precipitation on clear air returns using a combination of surface rainfall measurements and co-located VHF and UHF radar observations.

\section{Instruments and measurement strategy}

The NERC MST radar at Aberystwyth $\left(52.4^{\circ} \mathrm{N}, 4.1^{\circ} \mathrm{W}\right)$, described in Vaughan (2002), operates at a frequency of $46.5 \mathrm{MHz}$ and has a peak transmitted power of $160 \mathrm{~kW}$. The antenna consists of a 20 by 20 array of four element Yagi aerials covering an area of $110 \mathrm{~m}$ by $110 \mathrm{~m}$. The radar beam has a one-way, half-power, half-width of $1.5^{\circ}$ and it can be steered in sixteen possible directions. These include the vertical and at angles of $4.2,6.0,8.5$ and $12.0^{\circ}$ off-vertical in a variety of azimuths.

Several recent studies have described methods used to derive parameters from Doppler spectra. Normally, these processing schemes aim to determine the returned signal power, Doppler shift and spectral width associated with the clear air returns observed at VHF frequencies. Studies which discuss this type of analysis include Barth et al. (1994), Hocking (1997), Hooper (1999), and May and Strauch (1998). More complicated processing schemes can also be used to attempt to separate the characteristics of any precipitation signal from the clear air signal (Wakasugi et al., 1986; Rajopadhyaya et al., 1994). In this study, the standard processing scheme used by the NERC MST radar is used in a statistical examination of the data. A more complicated scheme, similar to that described in Rajopadhyaya et al. (1994), is also used to identify the precipitation and clear air signals in two case studies, to show the difficulty in separating these signals at low rainfall rates.

The simple, single-peak spectral processing technique used has been developed for general purpose use rather than specifically for precipitation conditions. The mean noise power spectral density (PSD) is evaluated using the objective algorithm of Hildebrand and Sekhon (1974). The peak PSD within each spectrum is initially assumed to relate to the desired clear air radar return (subsequent reliability flagging, based on the time continuity of the Doppler shifts, is found to be effective at removing those spectra for which this assumption is clearly false). The spectral limits of the signal are bound by those points at which the PSD, to either side of the peak PSD, first drops below the mean noise PSD. For strong signals, the limits are further restricted by identifying those points at which the PSD first drops to 0.01 of the peak PSD. The principal spectral parameters of signal power, Doppler 
Table 1. The mean VHF signal power is shown averaged over the height range indicated during periods where the indicated rainfall threshold was and was not exceeded. In addition, the number of positive and negative changes are shown in the mean signal power associated with rainfall and the number of significant decreases in the signal power associated with periods of surface rainfall above the indicated threshold. The surface rainfall is observed by a tipping bucket rain gauge co-located with the VHF radar.

\begin{tabular}{llllll}
\hline $\begin{array}{l}\text { Height range } \\
(\mathrm{km})\end{array}$ & $\begin{array}{l}\text { Surface rainfall } \\
\text { threshold } \\
\left(\mathrm{mm} \mathrm{h}^{-1}\right)\end{array}$ & $\begin{array}{l}\text { Mean VHF signal } \\
\text { power during } \\
\text { periods when the } \\
\text { surface rainfall } \\
\text { threshold was } \\
\text { exceeded }(\mathrm{dB})\end{array}$ & $\begin{array}{l}\text { Mean VHF signal } \\
\text { power during } \\
\text { periods when the } \\
\text { surface rainfall } \\
\text { threshold was NOT } \\
\text { exceeded }(\mathrm{dB})\end{array}$ & $\begin{array}{l}\text { Values (posi- } \\
\text { tive/negative) }\end{array}$ & $\begin{array}{l}\text { Significant } \\
\text { decreases/Total }\end{array}$ \\
& & 64.1 & 66.7 & $4 / 29$ & $20 / 33$ \\
\hline $2-4$ & 0.0 & 57.4 & 57.8 & $12 / 21$ & $9 / 33$ \\
$4-6$ & 0.0 & 31.2 & 31.0 & $21 / 12$ & $4 / 33$ \\
$16-18$ & 0.0 & 64.0 & 66.3 & $8 / 25$ & $16 / 33$ \\
$2-4$ & 3.0 & 56.9 & 57.8 & $13 / 20$ & $8 / 33$ \\
$4-6$ & 3.0 & 31.1 & 31.0 & $12 / 21$ & $2 / 33$ \\
$16-18$ & 3.0 & & & & \\
\hline
\end{tabular}

shift and spectral width are then calculated within these limits by the standard method described by Woodman (1985). Problems can arise when hydrometeor returns and clear air returns both contribute to the observed radar return signals from the lower troposphere. It is only under conditions of very heavy precipitation that the two components, observed by this radar, are distinct (Hooper et al., 2003). It is more common for the components to overlap so that both are identified as belonging to a single signal. Techniques are available to separate strongly overlapping signals, but Fourier-like techniques generally provide poor results because of the lack of resolution (Boyer et al., 2003). Under such conditions, using the simpler processing scheme, the principal spectral parameters are not representative of the clear air returns alone. In particular the signal power will be overestimated and the spectral width can no longer be interpreted in terms of turbulence intensity (Chu and Lin, 1994). Nevertheless, since the aim of this paper is to demonstrate the reduction in clear air radar return power associated with precipitation, this shortcoming will only reduce the magnitude of the effect in cases where the signal power associated with precipitation is appreciable. This limitation of the current study is discussed in detail in Sect. 4.

Although the radar is operated in a multi-beam mode, attention will be confined to the vertical beam observations in this study. An 8- $\mu \mathrm{s}$ pulse which has a phase code of $2 \mu \mathrm{s}$ (giving a range resolution of $300 \mathrm{~m}$ ), is used with an interpulse period of $320 \mu s$. The Doppler spectra are derived using 1024-point coherent integration and 64 point discrete Fourier transforms. The minimum altitude that atmospheric returns can be observed from is $1.7 \mathrm{~km}$.

The surface rainfall rate used in this study is measured by an ARG100 raingauge. The amount of rain collected is measured by the well-proven tipping bucket method. A contact closure at each tip is recorded by a datalogger and the number of tips during a 10-min interval is recorded. Thus, the rain gauge measures the integrated rainfall for a given time inter- val. In addition, use is made of data from a (UK) Met Office $915 \mathrm{MHz}$ (UHF) boundary-layer wind-profiler which was colocated with the NERC MST radar between 17 November 1999 and 11 March 2002. The useful altitude coverage of the UHF profiler varies with the measurement mode utilised and atmospheric conditions and generally only extends significantly above $2 \mathrm{~km}$ when precipitation is present. Although the cycle time for observations is of the order of a few minutes, the available data represents a consensus average over 30 minutes.

\section{Results}

This study uses data from the NERC MST Radar facility at Aberystwyth in mid-Wales. Examples of the effect of precipitation on the observed signal power are shown after a statistical analysis of the effect of precipitation on VHF returns. To examine the role of precipitation on clear air returns statistically, a number of days associated with high rainfall rates at the surface were selected. High rainfall days were defined in this study as days where the surface rainfall rate was greater than $6 \mathrm{~mm} \mathrm{~h}^{-1}$ for a continuous period greater than or equal to 20 minutes. A total of 33 days during the calendar year 2001 were selected using this criterion. Later in the statistical analysis co-located UHF wind-profiler measurements are used to examine the statistical relationship between precipitating cloud regions (associated with large signal-to-noise ratios in the UHF signal at high altitudes) and the VHF returns. A subset of 23 days from the 33 days previously selected is used in this analysis because of a lack of simultaneous UHF data during many days.

\subsection{Statistical analysis}

Table 1 shows the mean signal power, for three altitude regions, associated with surface precipitation and nonprecipitation conditions. As a check, two different threshold 
Table 2. The mean VHF spectral width is shown averaged over the height range indicated during periods where the indicated rainfall threshold was and was not exceeded. In addition, the number of positive and negative changes are shown in the spectral width as well as the number of significant increases in the spectral width associated with periods of surface rainfall above the indicated threshold. The surface rainfall is observed by a tipping bucket rain gauge co-located with the VHF radar.

\begin{tabular}{|c|c|c|c|c|c|}
\hline $\begin{array}{l}\text { Height range } \\
(\mathrm{km})\end{array}$ & $\begin{array}{l}\text { Surface rainfall } \\
\text { threshold } \\
\left(\mathrm{mm} \mathrm{h}^{-1}\right)\end{array}$ & $\begin{array}{l}\text { Mean VHF spectral } \\
\text { width during } \\
\text { periods when the } \\
\text { surface rainfall } \\
\text { threshold was } \\
\text { exceeded }\left(\mathrm{m} \mathrm{s}^{-1}\right)\end{array}$ & $\begin{array}{l}\text { Mean VHF spectral } \\
\text { width during } \\
\text { periods when the } \\
\text { surface rainfall } \\
\text { threshold was NOT } \\
\text { exceeded }\left(\mathrm{m} \mathrm{s}^{-1}\right)\end{array}$ & $\begin{array}{l}\text { Values (posi- } \\
\text { tive/negative) }\end{array}$ & $\begin{array}{l}\text { Significant } \\
\text { increases/Total }\end{array}$ \\
\hline $2-4$ & 0.0 & 0.41 & 0.27 & $32 / 1$ & $31 / 33$ \\
\hline $4-6$ & 0.0 & 0.31 & 0.23 & $31 / 2$ & $26 / 33$ \\
\hline $16-18$ & 0.0 & 0.22 & 0.22 & $17 / 16$ & $4 / 33$ \\
\hline $2-4$ & 3.0 & 0.48 & 0.27 & $32 / 1$ & $24 / 33$ \\
\hline $4-6$ & 3.0 & 0.34 & 0.24 & $28 / 5$ & $16 / 33$ \\
\hline $16-18$ & 3.0 & 0.22 & 0.21 & $15 / 18$ & $3 / 33$ \\
\hline
\end{tabular}

rainfall rates $\left(0 \mathrm{~mm} \mathrm{~h}^{-1}\right.$ and $\left.3.0 \mathrm{~mm} \mathrm{~h}^{-1}\right)$ are used to distinguish precipitation conditions from non-precipitation ones. When the mean signal power is calculated from VHF data between 2 and $4 \mathrm{~km}$, using a rainfall threshold of $0 \mathrm{~mm} \mathrm{~h}^{-1}$ (rain and no rain periods), a clear decrease of $2.6 \mathrm{~dB}$ is observed during rainfall. Between 4 and $6 \mathrm{~km}$ this difference decreases to $0.4 \mathrm{~dB}$ and at $16-18 \mathrm{~km}$ it is only $0.2 \mathrm{~dB}$. This decrease indicates that this change is not associated with increased noise levels at all altitudes caused by rain static. The observed altitude dependence also seems to suggest that precipitation between 2 and $4 \mathrm{~km}$ causes this change. When the rainfall threshold is increased to $3.0 \mathrm{~mm} \mathrm{~h}^{-1}$ the difference between the signal powers remains approximately the same for measurements between 2 and $4 \mathrm{~km}$. This suggests that the effect observed is associated with changes in the clear air returns because this increase in rainfall rate would be associated with increased reflectivity for a precipitation signal (Doviak and Zrnić, 1993). Thus, an increase in signal power would be observed if the precipitation signal made up an appreciable amount of the observed signal power. However, separating VHF signal power data into periods of heavier (rate greater than $3.0 \mathrm{~mm} \mathrm{~h}^{-1}$ ) and lighter (rate less than $3.0 \mathrm{~mm} \mathrm{~h}^{-1}$ ) surface rainfall changes the results for the 4$6 \mathrm{~km}$ altitude region, giving rise to a difference of $0.9 \mathrm{~dB}$. It is suggested that this difference is caused by the larger vertical extent of convective precipitation which is generally responsible for the highest rainfall rates at this location. Table 1 also shows the number of events where the variation in the mean changes significantly at the $95 \%$ level. Examination shows that over half the events display a statistically significant decrease in signal power during rainfall for averages derived from data between 2 and $4 \mathrm{~km}$.

Examination of Table 2 shows that the vertical spectral width, which is corrected for the effect of beam broadening, observed during periods above the surface rainfall threshold is larger than that during periods when the surface rainfall threshold is not exceeded. Table 2 also shows the number of events when the spectral width increase during rainfall is significant. It is interesting to note that this effect is much more pronounced than the signal power decrease, with nearly all days (31 out of 33) showing a significant increase in spectral width. This statistical increase either suggests that a combination of clear air and precipitation returns is observed by the standard signal processing scheme used by the VHF radar or that a large contribution is observed from turbulent scatter inside precipitating clouds. If this increase in the spectral width during periods of rainfall is associated with a combination of clear air and precipitation returns, it is highly significant; this is because it indicates that the signal power observed is also a combination of both precipitation and clear air returns, suggesting that the true reduction of the clear air return must be even larger than indicated since some part of the observed signal power will be associated with the precipitation return. This is discussed further in Sect. 4 where it is concluded that the signal processing scheme can in cases produce a spectral width which can be identified with both precipitation and clear air returns.

A closer examination into whether the change in the VHF signal return is associated with precipitation is achieved using the signal-to-noise ratio (SNR) between 2 and $4 \mathrm{~km}$ of a UHF wind profiler. Table 3 displays the mean VHF signal power averaged over the 2 to $4 \mathrm{~km}$ range during periods where the mean UHF SNR averaged between 2 and $4 \mathrm{~km}$ is greater or less than a threshold value. During the periods where the mean SNR of the UHF signal is greater than $0 \mathrm{~dB}$, the signal observed by the VHF radar is $3.6 \mathrm{~dB}$ smaller than during the other periods. It should be noted at this point that if the subset of data used for the UHF data comparison is processed using a rainfall threshold of $0 \mathrm{~mm} \mathrm{~h}^{-1}$, the difference is only $2.7 \mathrm{~dB}$. Thus, regions of precipitation identified by the UHF profiler seem to clearly correspond to regions of low signal power in the VHF return. This supports the 

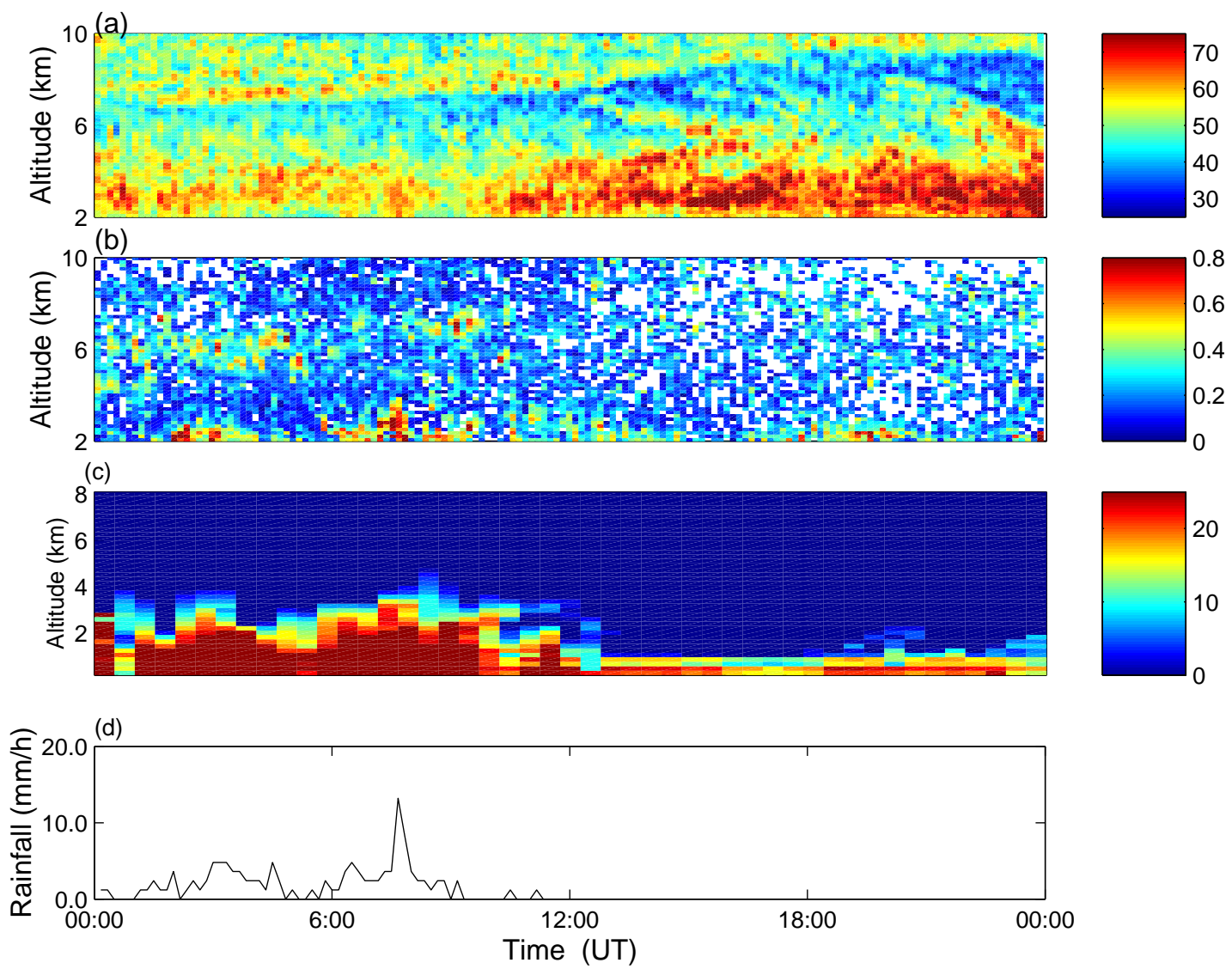

Fig. 1. Time-height contour plots of (a) vertical signal power $(\mathrm{dB}),(\mathbf{b})$ vertical corrected spectral width ( $\mathrm{m} \mathrm{s}^{-1}$ ) observed by the VHF radar, (c) the vertical signal-to-noise ratio measured by a co-located UHF wind profiler $(\mathrm{dB})$ and (d) the variation of surface rainfall observed by a tipping bucket rain gauge on 17 May 2001.

conclusion that the clear air return is reduced in periods of precipitation. It also suggests that the variations in Table 1 and Table 2 may represent a lower bound on the effect, since in many cases enhanced returns in the UHF data associated with precipitation do not correspond to periods of surface rainfall.

To clarify the processes and effects observed three different case studies are examined.

\subsection{Case study 1: 17 May 2001}

Figure 1 displays time-height contour plots of the vertical signal power and corrected spectral width observed by the VHF radar and the corresponding surface rainfall rate measured by a tipping bucket rain gauge. The negative correlation between VHF signal power and surface rainfall rate expected from the statistical study is clearly evident at the low altitudes. The positive correlation expected between beambroadening corrected spectral width and surface rainfall rate is also apparent but not as clearly.

Examination of the UHF signal-to-noise ratio during this day, shown in Fig. 1c, displays enhancements between 2 and $3 \mathrm{~km}$ during the period of intense rainfall. This indicates that hydrometeors are present in the range where the VHF signal power is reduced, which again implies that the signal is affected by precipitation or some process associated with the precipitating clouds.

Examination of the UHF signal-to-noise ratio profiles during the period of rainfall (not shown) indicates the presence of a bright band during most periods. Previously, Williams et al. (1995) used the presence or absence of a bright band in the UHF signal profile in an automated algorithm to distinguish between convective or stratiform precipitating rain clouds. Thus, this data suggests that during stratiform rain a clear VHF signal power reduction can be observed. The decrease in VHF signal power suggests that in this case the bright band phenomenon is not observed by the VHF radar, since this is associated with a signal enhancement. The reduction observed is not as clear in rainfall periods associated with convection, where signal power can sometimes increase during rainfall. A possible explanation for these cases is the lofting of lower tropospheric humid air into the upper troposphere which produces a region with high humidity and therefore large clear air returns. However, an examination based on different precipitating cloud types is outside the scope of the present study because of the relatively small data sample (only 33 days). 
Table 3. The mean VHF signal power is shown averaged over the 2 to $4 \mathrm{~km}$ height range during periods where the UHF signal-to-noise ratio was greater or less than the thresholds indicated. The number of positive and negative changes are also shown in the VHF signal power as well as the number of days where a significant decrease in signal power was associated with large UHF signal-to-noise ratios.

\begin{tabular}{lllll}
\hline $\begin{array}{l}\text { UHF SNR } \\
\text { between 2 and } \\
4 \mathrm{~km}(\mathrm{~dB})\end{array}$ & $\begin{array}{l}\text { Mean VHF signal power } \\
\text { during periods when the } \\
\text { UHF SNR threshold is } \\
\text { exceeded }(\mathrm{dB})\end{array}$ & $\begin{array}{l}\text { Mean VHF signal power } \\
\text { during periods when the } \\
\text { UHF SNR threshold is } \\
\text { NOT exceeded }(\mathrm{dB})\end{array}$ & $\begin{array}{l}\text { Values (posi- } \\
\text { tive/negative) }\end{array}$ & $\begin{array}{l}\text { Significant } \\
\text { decreases/Total }\end{array}$ \\
\hline 0.0 & 63.3 & 66.9 & $4 / 19$ & $17 / 23$ \\
5.0 & 63.1 & 66.7 & $5 / 18$ & $16 / 23$ \\
\hline
\end{tabular}
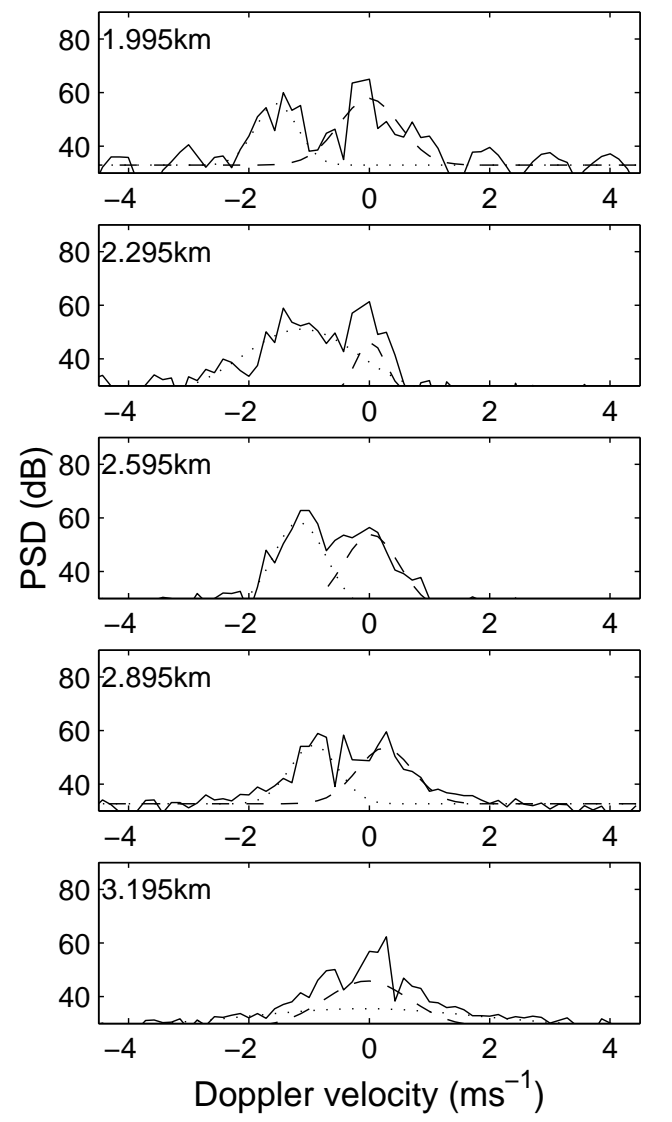
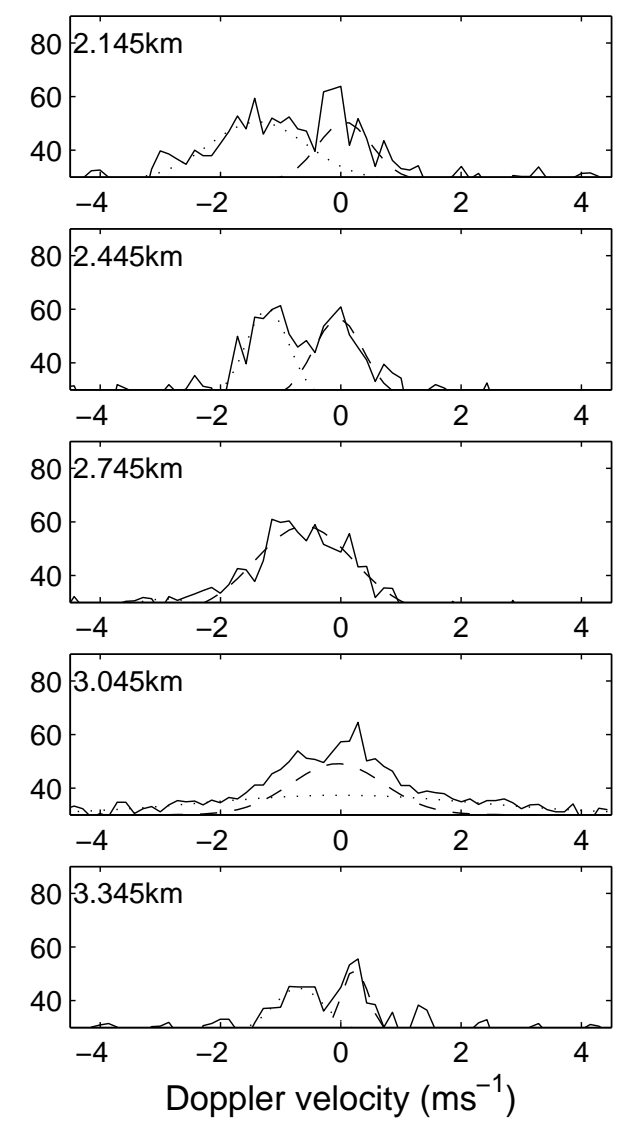

Fig. 2. VHF Doppler spectra taken at 07:24 UT on the 17 May 2001, the observation altitude being shown for each spectrum. The black line represents the raw data, and the dotted and dashed lines show fits to any possible Rayleigh or clear air echoes using a technique similar to that described in Rajopadhyaya et al. (1994).

VHF radar Doppler spectra at 07:24 UT on the 17 May 2001 (close to the peak in the surface rainfall rate of $13.2 \mathrm{~mm}$ $\mathrm{h}^{-1}$ ) are shown in Fig. 2. Examination of these spectra shows a possible secondary peak associated with a precipitation echo in nearly all the spectra displayed, with the clearest secondary peaks being observed at lower altitudes. It should be noted that negative Doppler velocity corresponds to downward motion. The width of the echoes is large at higher altitudes, which is likely to indicate that the signal is associated with a combination of the clear air and precipitation return. It should be reiterated that if this is the case, the decrease in clear air returns during precipitation will be larger than indicated, since some part of the observed signal power would be associated with the precipitation return. This possibility has previously been indicated by the statistical increase in the spectral width observed during rainfall. Figure 2 also shows fits to possible clear air and Rayleigh scattering peaks using a technique similar to that described in Rajopadhyaya et al. (1994). It should be noted that examination of these fits and their residuals (not shown) displays the difficulty in trying to separate the observed data into these two signals, particularly at higher altitudes. 

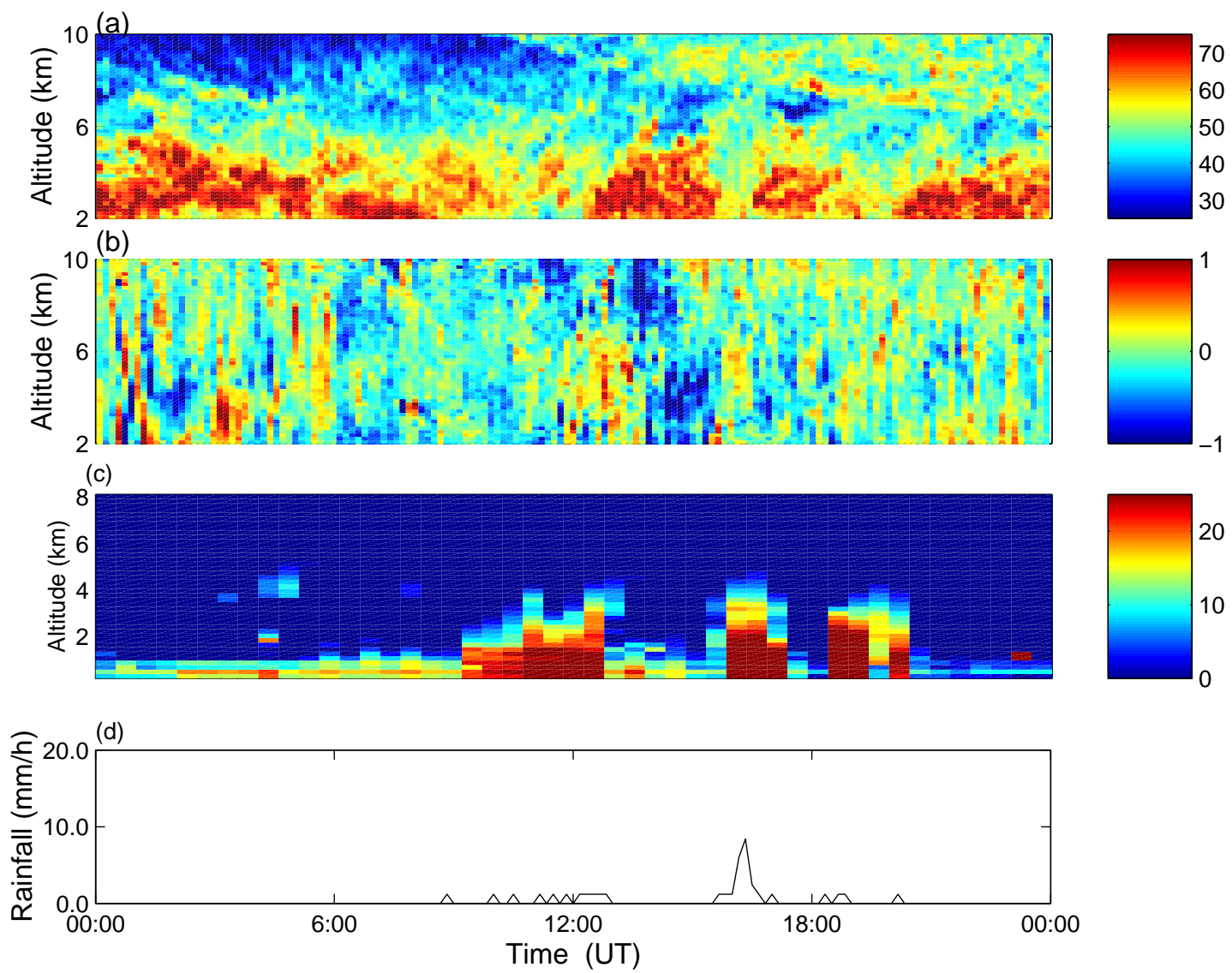

Fig. 3. Time-height contour plots of (a) vertical signal power $(\mathrm{dB}),(\mathbf{b})$ vertical velocity $\left(\mathrm{m} \mathrm{s}^{-1}\right)$ observed by the VHF radar, (c) the vertical signal-to-noise ratio measured by a co-located UHF wind profiler $(\mathrm{dB})$ and $(\mathbf{d})$ the variation of surface rainfall observed by a tipping bucket rain gauge on 22 January 2001 .

While the statistical analysis suggests that precipitation is associated with decreases in signal power and increases in spectral width, another possible interpretation of these changes is possible, namely that the change in air mass which usually occurs during the period of rainfall causes these changes rather than the precipitation. This interpretation could indeed be used to explain the change observed in Fig. 1. Unfortunately, at midlatitude sites in the Northern Hemisphere, and particular in the UK, the predominant weather pattern associated with precipitation is one in which frontal systems cross the region, in the case of the UK, from west to east. Thus, an attempt to deconvolve the two possible causes of the observed changes in signal power and spectral width is difficult. The second case study attempts to address this possibility and a further analysis in Sect. 4 also discusses this possibility. Conclusions based on these results and previous published material are then made.

\subsection{Case study 2: 22 January 2001}

Figure 3 shows time-height contour plots of the vertical signal power and vertical velocity observed by the VHF radar and the corresponding surface rainfall rate measured on 22 January 2001. Examination of the period indicates that in- termittent rainfall is observed over a period of roughly $12 \mathrm{~h}$ from 09:00 to 21:00 UT. Comparison of the variation of signal power at altitudes below $4 \mathrm{~km}$ and the surface rainfall rate indicates that the regions associated with surface rainfall correspond well to regions of decreased vertical signal power. However, examination also suggests that outside the periods of rainfall the vertical signal power is similar throughout the period specified. This suggests that the reductions of signal power observed are closely related to periods of rainfall. Thus, changes in air mass are not a factor at least in this case. However, it is still possible that the reduction in signal power is associated with the frontal zone between air masses and this is discussed later in Sect. 4. It should also be noted that the vertical velocities associated with the periods of surface rainfall are relatively small and sometimes upward. Thus, they are indicative of measurements whose derived Doppler velocity is associated with clear air returns rather than the terminal velocity of hydrometeors. Similar examination of the other data used in this study shows that this is true in the majority of cases, with the data displayed in Fig. 2 being an example of one of these periods. 

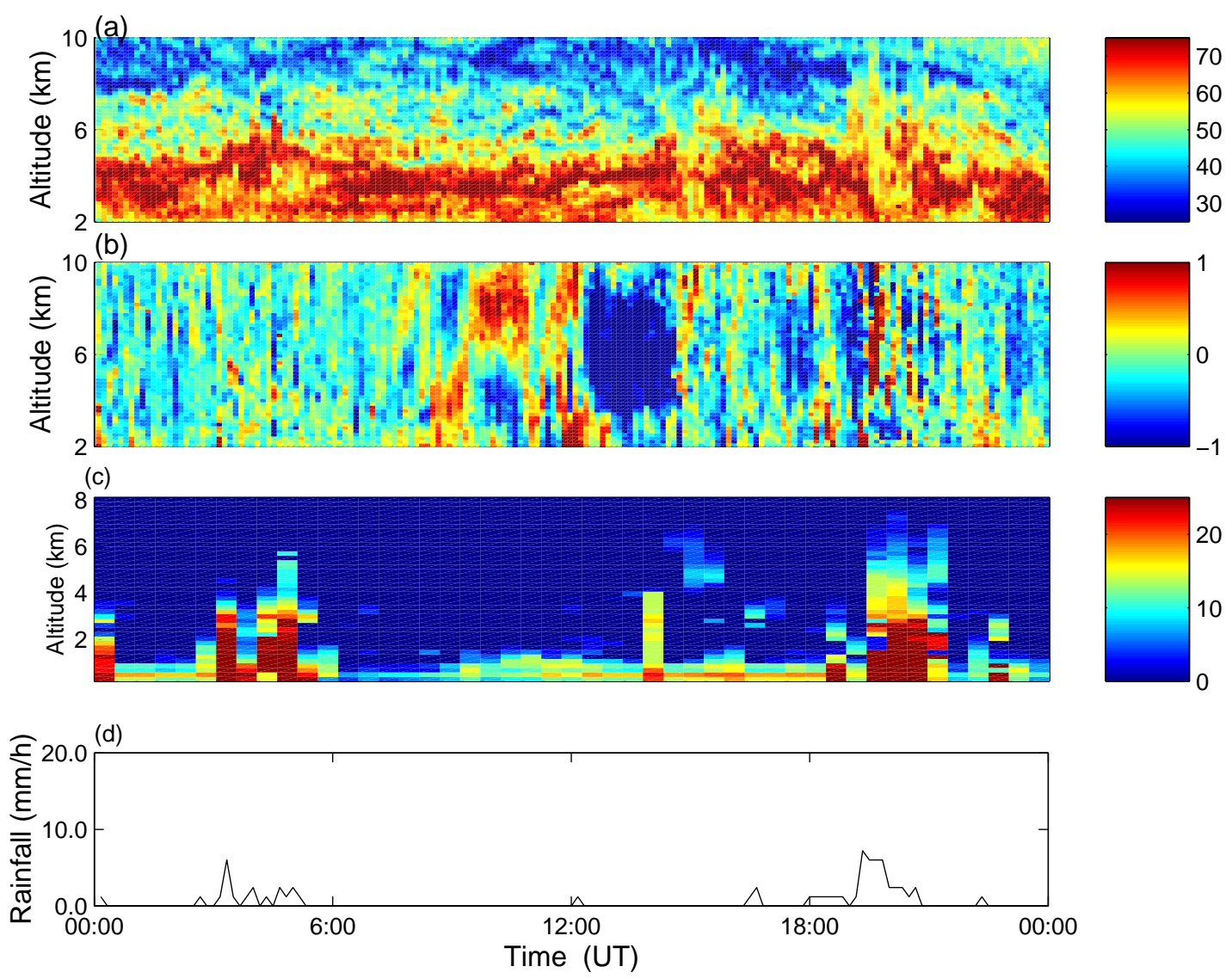

Fig. 4. Time-height contour plots of (a) vertical signal power $(\mathrm{dB}),(\mathbf{b})$ vertical velocity $\left(\mathrm{m} \mathrm{s}^{-1}\right)$ observed by the VHF radar, $(\mathbf{c})$ the vertical signal-to-noise ratio measured by a co-located UHF wind profiler $(\mathrm{dB})$ and $(\mathbf{d})$ the variation of surface rainfall observed by a tipping bucket rain gauge on 5 October 2001 .

\subsection{Case study 3: 5 October 2001}

Figure 4 displays time-height contour plots of the vertical signal power and vertical velocity observed by the VHF radar and the corresponding surface rainfall rate measured by a tipping bucket rain gauge measured on the 5 October 2001 . Comparison of the vertical signal power and the surface rainfall in this case shows a less clear negative relationship than observed in Fig. 1. Examination also indicates that on this day enhanced vertical velocities associated with mountain wave activity are observed, but that no clear enhancements in vertical velocity are related to precipitation, in particular no large downward vertical velocity enhancements are observed during precipitation periods. However, a possible region of convection, identified by large upward velocities and enhanced signal power at higher altitudes, may be observed at 20:30 UT.

Examination of the UHF SNR during this day (shown in Fig. 4c) displays enhancements between 2 and $6 \mathrm{~km}$ during periods of intense rainfall. This indicates that hydrometeors are present in the range where the VHF signal power is reduced, which implies that the signal is affected by precipitation. It is particularly interesting to note in this case that a region which displays a decrease in the signal power ob- served by the VHF radar at approximately 15:00 UT does not correspond to surface rainfall, but does match well with a period of enhanced SNR observed by the UHF wind profiler at roughly 15:00 UT. This suggests that a signal associated with precipitating cloud is observed by both radars, but that the precipitation does not reach the surface because of either advection or evaporation.

\section{Discussion}

The first question that arises from the statistical analysis and case studies shown is whether the reductions in signal power and increases in spectral width observed are real or processing anomalies. The most obvious flaw in the processing used is that a simple procedure has been used to identify regions of signal and that no great effort has been made to separate the precipitation signal from the clear air return. Many studies have shown that this is an important omission (Rao et al., 1999; Chu et al., 1991). However, all of these studies have also indicated that the signal power associated with precipitation is usually much smaller than that related to clear air returns, apart from periods associated with very high rainfall rates or in altitude regions related to melting precipitation, 
Table 4. The mean VHF signal power is shown averaged over the height range indicated during periods where the indicated rainfall threshold was and was not exceeded. In addition, the number of positive and negative changes are shown in the mean signal power associated with rainfall as well as the number of significant decreases in the signal power associated with periods of surface rainfall above the indicated threshold. The surface rainfall is observed by a tipping bucket rain gauge co-located with the VHF radar.

\begin{tabular}{llllll}
\hline $\begin{array}{l}\text { Height range } \\
(\mathrm{km})\end{array}$ & $\begin{array}{l}\text { Surface rainfall } \\
\text { threshold } \\
\left(\mathrm{mm} \mathrm{h}^{-1}\right)\end{array}$ & $\begin{array}{l}\text { Mean VHF signal } \\
\text { power during } \\
\text { periods when the } \\
\text { surface rainfall } \\
\text { threshold was } \\
\text { exceeded }(\mathrm{dB})\end{array}$ & $\begin{array}{l}\text { Mean VHF signal } \\
\text { power during } \\
\text { periods when the } \\
\text { surface rainfall } \\
\text { threshold was NOT } \\
\text { exceeded (dB) }\end{array}$ & $\begin{array}{l}\text { Values (posi- } \\
\text { tive/negative) }\end{array}$ & $\begin{array}{l}\text { Significant } \\
\text { decreases/Total }\end{array}$ \\
& & 72.6 & 75.6 & $3 / 30$ & $18 / 33$ \\
\hline $2-4$ & 0.0 & 66.2 & 66.6 & $13 / 20$ & $10 / 33$ \\
$4-6$ & 0.0 & 40.0 & 39.9 & $13 / 20$ & $6 / 33$ \\
$16-18$ & 0.0 & 72.2 & 75.1 & $7 / 26$ & $13 / 33$ \\
$2-4$ & 3.0 & 65.6 & 66.6 & $14 / 19$ & $7 / 33$ \\
$4-6$ & 3.0 & 40.0 & 39.9 & $13 / 20$ & $6 / 33$ \\
$16-18$ & 3.0 & & & & \\
\hline
\end{tabular}

the bright-band effect. Thus, if the current study uses periods outside very heavy rainfall the majority of the time and the bright band effect is not important, the analysis associated with signal power should be valid. The effect of overlapping precipitation and clear air returns may still have an important impact on spectral width even when these conditions are met.

Before testing the observations for the impact of large rainfall rates and enhancements associated with the bright band it is worth noting that the statistical analysis was completed using two separate signal processing schemes. This is because a revised version of the signal processing system was implemented during the period of this study. The older scheme which has not been detailed is mentioned in Slater et al. (1991). Both of these schemes are associated with single peak spectral processing, but the two schemes have a number of differences, for example, the old scheme uses a peak-tracking algorithm to ensure consistent observations are made and uses a different noise level derivation technique than the new scheme. Thus, comparison of results from the new and old scheme allows us to determine whether the results are likely to be applicable to other processing schemes and thereby other radar. Table 4 indicates the changes in signal power associated with periods inside and outside surface rainfall for the old scheme. Comparison of Table 4 with Table 1 indicates that while the absolute value of the signal power has changed dramatically, the number of days which show statistically significant decreases during rainfall is similar and that the difference in signal power inside and outside periods of surface rainfall is also very similar, for the altitude range $2-4 \mathrm{~km}$ and for a rainfall rate threshold of $0.0 \mathrm{~mm} \mathrm{~h}^{-1}$, $2.6 \mathrm{~dB}$ and $3.0 \mathrm{~dB}$ for the new and old processing schemes, respectively.

The rainfall rate necessary to produce Rayleigh scattered signals greater than the clear air returns was derived by Ralph (1995) to be $8.4 \mathrm{~mm} \mathrm{~h}^{-1}$ for a radar with a frequency of $50 \mathrm{MHz}$. The wavelength dependence of Rayleigh scattering and the clear air returns means that this rainfall rate will be marginally higher for the observations indicated in this study because of the lower operating frequency of the NERC MST radar $(46.5 \mathrm{MHz})$. Examination of the rainfall data indicates that for the 33 days selected, which all contain rainfall rates greater than $6 \mathrm{~mm} \mathrm{~h}^{-1}$, surface rainfall is observed approximately $20 \%$ of the time. Of this rainfall only $0.5 \%$ of it is above the $8.4 \mathrm{~mm} \mathrm{~h}^{-1}$ rain rate indicated by Ralph (1995). Thus, in the vast majority of cases the surface rainfall is not strong enough to warrant using a more complicated signal processing scheme.

The possibility is now examined that the bright band effect may distort the observations, particularly in the $2-4 \mathrm{~km}$ range where the reduction in signal power is most clearly observed. To examine the occurrence of the bright band and its possible affect the altitude of the $0^{\circ} \mathrm{C}$ isotherm was determined from nearby radiosonde data taken at Aberporth, approximately $50 \mathrm{~km}$ from the radar site. Those days where the $0^{\circ} \mathrm{C}$ isotherm was lower than $2 \mathrm{~km}$ were selected. It was found that of the nine days observed, where the $0^{\circ} \mathrm{C}$ isotherm was below $2 \mathrm{~km}$, five displayed significant decreases in the signal power during rainfall. Thus, the proportion of days where a significant decrease at the $95 \%$ level was observed seems very similar for the whole data set and the subset where the $0^{\circ} \mathrm{C}$ isotherm was below $2 \mathrm{~km}$. This suggests that the bright band does not have a significant affect on the results of this study. It should be noted that this may be associated with the fact that the statistical analysis uses averages over long periods (greater than several hours typically) and over an extended altitude range. This lack of impact is also possibly because while the bright band has been shown to have a strong affect on returns in the Tropics (Chu et al., 1991; Rao et al., 1999), its structure and magnitude are very different at mid-latitudes. For example, Rao et al. (1999) indicates that the depth of the bright band observed by the Indian MST radar is approximately $900 \mathrm{~m}$, while studies at midlatitudes by Fabry and Zawadzki (1995), Gray et al. (2001) and Klassen (1988) have indicated that the bright-band depth 


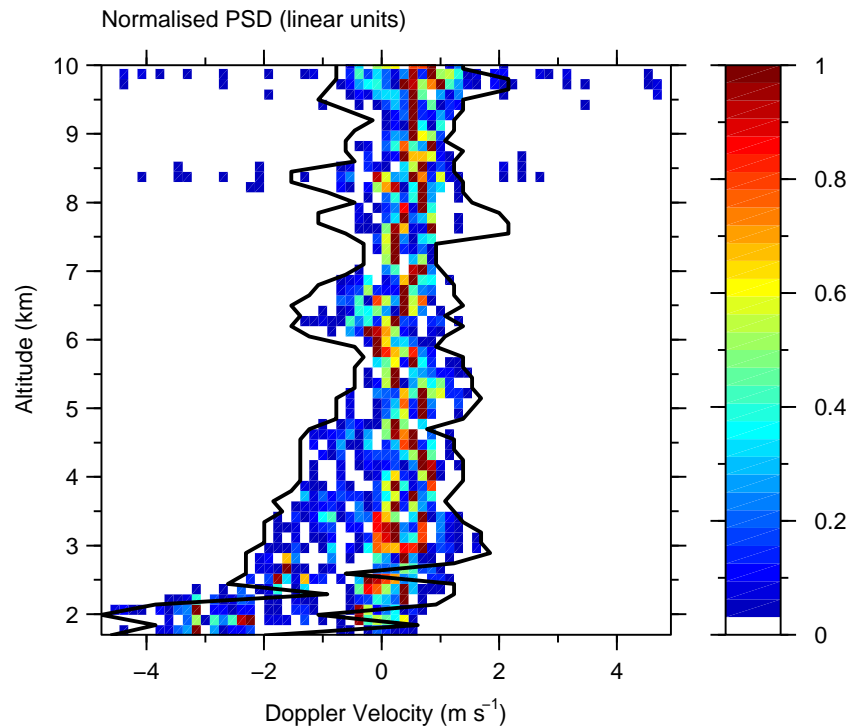

Fig. 5. Normalised Doppler power spectra for the vertical beam made at 15:00 UT on 14 June 2001.

varies between $150-600 \mathrm{~m}, 100-400 \mathrm{~m}$ and $200-600 \mathrm{~m}$, respectively. It should be noted that the method used to determine the bright band depth used in Klassen (1988) uses turning points of the terminal velocity. Gray et al. (2001) indicates that this method produces greater bright band depths than when the region of the bright band is defined by determining the altitude of minimum and maximum rate of change in the reflectivity. Thus, the larger values indicated in Klassen (1988) should be used with some caution when only the region of enhanced reflectivity is sought rather than the region of melting. In order to attribute the reductions in signal power observed to the presence of precipitation, it is necessary to rule out other factors which may contribute to the reduction. Specifically, it is important that changes in air mass near frontal regions, which are associated with rainfall, are not the cause of the signal reductions that have been linked to precipitation. Changes in signal power at VHF wavelengths have been used to study frontal activity in some detail (Caccia and Cammas, 1998; Browning et al., 1998). Frontal regions can be identified due to the enhanced stability associated with them. However, this enhancement is usually observed at higher altitudes where there is little humidity, allowing the static stability terms of the refractive index gradient to dominate (Lucas et al., 2001). The focus of this study is in the region $2-4 \mathrm{~km}$, so these enhancements can be ignored in this case. The enhanced reflectivities also tend to become organised as inclined layers due to the sloping nature of the front itself (Browning et al., 1998). The regions of signal power decrease covered in this paper show very little sloping structure, suggesting that they are not associated with frontal regions. It should be noted that precipitation in the UK is predominantly related to cold, warm and occluded fronts. The different air mass changes that correspond to these frontal passages would suggest that increases as well as decreases should occur in the signal power if the

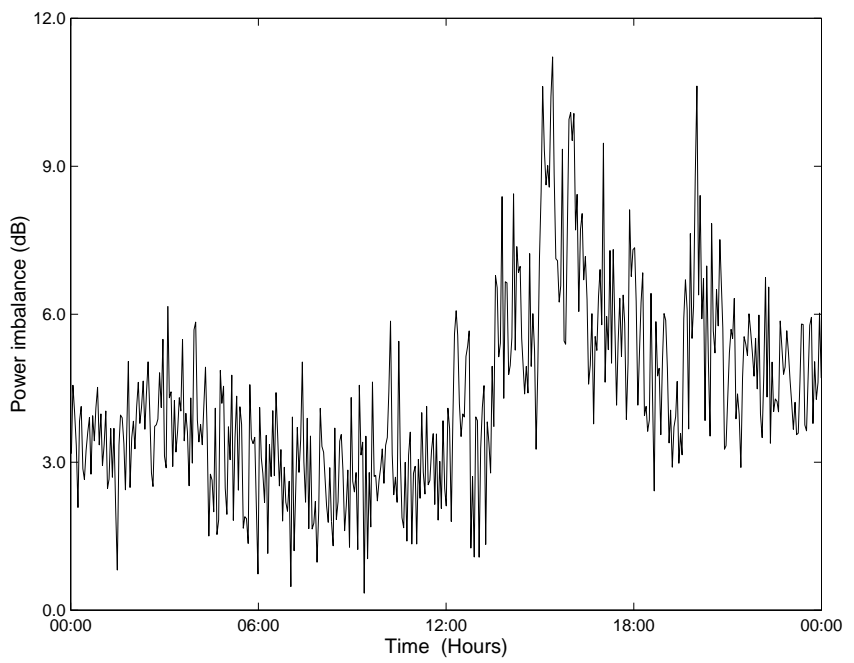

Fig. 6. The mean power imbalance observed by the VHF radar between the vertical and the six degree off-vertical beams averaged over the region 2 to $4 \mathrm{~km}$ for observations made on 17 May 2001 .

change is associated with air mass changes. This does not occur; no significant increases in signal power are observed thus suggesting air mass changes are not a factor, statistically. The balance of published material also seems to support the interpretation that the reductions in signal power observed are associated with precipitation rather than frontal regions (Chu et al., 1991; Rao et al., 1999; Vaughan and Worthington, 2000)

In addition, Fig. 5 shows the normalised Doppler power spectra for the vertical beam at 15:00 UT on 14 June 2001 . Figure 5 also indicates the bounds within which the spectral parameters are evaluated. It is noteworthy that in this period (which is related to a rainfall rate of $7.2 \mathrm{~mm} \mathrm{~h}^{-1}$ ) the processing scheme tends to identify both the precipitation and clear air peaks as belonging to a single signal at altitudes below $5 \mathrm{~km}$. This indicates the spectral width increase at least some times is associated with selection of both precipitation and clear air returns. Thus, it seems likely that the decrease in signal power observed is also associated with precipitation. In addition, this indicates that the signal power observed is also a combination of both precipitation and clear air returns, suggesting that the true reduction of the clear air return must be even larger than indicated in the statistical study, since some part of the observed signal power will be associated with the precipitation return.

Chu and Song (1998) suggests that the depletion of the clear air echo power can be attributed to the turbulent mixing between warm and humid in-cloud air, and cool and dry ambient air entrained into the cloud following a strong updraft. This conclusion can be tested by examining the vertical velocity field for the three days previously examined relative to the regions associated with depletion of the clear air returns. Assessment of the vertical velocity data on 17 May 2001 (not shown) does not indicate any strong updrafts associated with the reduction in the clear air returns. Figure $3 \mathrm{c}$ 
and Fig. 4c also show little evidence of strong updrafts. However, the presence of strong turbulent mixing cannot be ruled out. To further examine this possibility the signal power measured in the vertical beam relative to that measured by a six-degree off-vertical beam is assessed. Figure 6 shows the mean power imbalance between the vertical and the sixdegree beams' signal power for averages taken between 2 and $4 \mathrm{~km}$ on 17 May 2001. Comparison of Fig. 1a and Fig. 6 indicates that the signals observed are more isotropic during precipitation events. This change indicates that the type of scattering inside precipitating regions may be associated with turbulent scatter rather than Fresnel reflection which would lead to more anisotropic scatter. This result has previously been indicated by Vaughan and Worthington (2000) and suggests that Fresnel reflection might be reduced in precipitating clouds. However, both their study and the current work cannot determine whether this is a result of a reduction of metre-scale humidity structures in the clouds or some other process due to the limitations of the available data.

It is interesting to note that the Doppler spectra displayed in Fig. 2 clearly indicate the presence of signals associated with both clear air and precipitation returns. The rainfall rate at this period is approximately $13.2 \mathrm{~mm} \mathrm{~h}^{-1}$ and thus the precipitation signal should be much larger than the clear air return, according to the work detailed in Ralph (1995). In addition, the spectral width determined by the standard signal processing scheme represents the signal from a combination of both precipitation and clear air returns at a number of heights on a case study basis. This is noteworthy because it implies that the reduction in the VHF signal power associated with clear air returns must be larger than indicated because the signal power determined is a combination of both the clear air and precipitation return.

\section{Conclusions}

A statistical examination of VHF radar signal power during periods with and without surface rainfall suggests that the returned power is reduced by the presence of precipitating clouds. The process which causes this effect seems to be associated with a reduction in Fresnel reflection within precipitating clouds. This, in turn, may be due to a reduction of humidity gradients in clouds. However, the available data does not allow for a clear conclusion to be drawn about the reduced Fresnel reflection observed.

The corrected spectral width of the Doppler spectra is also significantly wider during periods of precipitation. This may be associated with the difficulty in separating precipitation and Bragg scatter echoes or increased turbulence inside precipitating clouds. If the enhanced spectral width observed during rainfall is associated with a contribution from Rayleigh scatter, which seems to be probable, then the effect on the clear air return is more substantial than suggested since at least some proportion of the signal measured will be associated with precipitation returns.
When UHF wind profiler measurements are compared with the signal power observed by the VHF radar a clear relationship between enhanced signal-to-noise ratios in the UHF wind profiler data (which are very likely to be associated with Rayleigh scattering from hydrometeors) and reductions in the VHF signal are also observed.

Three case studies display the clear relationship between reduced VHF signal power and surface rainfall or enhanced UHF radar returns. Typical Doppler spectra taken from 17 May 2001 and 14 June 2001 clearly indicate the possibility of echoes associated with a combination of the clear air and precipitation returns, thus suggesting that the standard signal processing scheme may reduce the impact of the observed effect.

Acknowledgements. Dr. McDonald would like to acknowledge grant U6518 awarded by the University of Canterbury. The MST Radar Facility at Aberystwyth is funded by the UK Natural Environment Research Council and the data presented in this paper has been kindly provided through the British Atmospheric Data Centre. We would also like to thank the (UK) Met Office who kindly provided the UHF wind profiler data to the British Atmospheric Data Centre.

Topical Editor U.-P. Hoppe thanks a referee for his help in evaluating this paper.

\section{References}

Atlas, D., Srivsastava, R. C., and Sekhon, R. S.: Doppler radar characteristics of precipitation at vertical incidence, Rev. Geophys., 11, 1-35, 1973.

Barth, M. F., Chadwick, R. B., and van de Klemp, D. W.: Data processing algorithms used by NOAA's wind profiler demonstration network, Ann. Geophysicae, 12, 518-528, 1994.

Boyer, E., Lazarbal, P., Adnet, C., and Petitdidier, M.: Parametric spectral moments estimation for wind profiling radar, IEEE Trans. Geosci. Remote Sens., 41, 1859-1868, 2003.

Browning, K. A., Jerrett, D., Nash, J., Oakley, T., and Roberts, N. M.: Cold frontal structure derived from radar wind profilers, Meteorol. Appl., 5, 67-74, 1998.

Caccia, J.-L. and Cammas, J.-L.: VHF-ST radar observations of an upper-level front using vertical and oblique-beam cn squared measurements, Mon. Wea. Rev., 126, 483 - 501, 1998.

Chu, Y.-H. and Lin, C.-H.: The severe depletion of turbulent echo power in precipitation observed using the Chung-Li VHF Doppler radar, Radio Sci., 29, 1311-1320, 1994.

Chu, Y. H. and Song, J.-S.: Observations of precipitation associated with a cold front using a VHF wind profiler and a ground-based optical rain gauge, J. Geophys. Res., 103, 11 401-11 409, 1998.

Chu, Y. H., Chian, L. P., and Liu, C. H.: The investigation of the atmospheric precipitation by using Chung-Li VHF radar, Radio Sci., 26, 717-729, 1991.

Currier, P. E., Avery, S. K., Balsley, B. B., Gage, K. S., and Ecklund, W. L.: Combined use of $50 \mathrm{MHz}$ and $915 \mathrm{MHz}$ wind profilers in the estimation of raindrop size distributions, Geophys. Res. Lett., 19, 1017-1020, 1992.

Doviak, R. J. and Zrnić, D. S.: Doppler Radar and Weather Observations, Academic Press, San Diego, 2nd edn., 1993. 
Fabry, F. and Zawadzki, I.: Long-term radar observations of the melting layer of precipitation and their interpretation, J. Atmos. Sci., 52, 838-851, 1995.

Gray, W. R., Cluckie, I. D., and J., Griffith, R. J.: Aspects of melting and the radar bright band, Meteorol. Appl., 8, 371 -379, 2001.

Hildebrand, P. H. and Sekhon, R. S.: Objective determination of the noise level in Doppler spectra, J. Appl. Meteorol., 13, 808-811, 1974.

Hocking, W. K.: System design, signal processing procedures, and preliminary results for the Canadian (London, Ontario) VHF atmospheric radar., Radio Sci., 32, 687-706, 1997.

Hooper, D. A.: Signal and noise level estimation for narrow spectral width returns observed by the Indian MST radar, Radio Sci., 34, 859-870, 1999.

Hooper, D. A., Reid, H. J., and Pavelin, E.: The signature of midlatitude convection observed by MST radar, in Proceedings of the Tenth International Workshop on Technical and Scientific Aspects of MST Radar, 2003.

Klassen, W.: Radar observations and simulation of the melting layer of precipitation, J. Atmos. Sci., 45, 3741-3753, 1988.

Lucas, C., May, P. T., and Vincent, R. A.: An algorithm for the detection of fronts in wind profiler data, Weather and Forecasting, 16, 234-247, 2001.

May, P. T. and Strauch, R. G.: Reducing the effect of ground clutter on wind profiler velocity measurements., J. Atmos. Ocean. Tech., 15, 579-586, 1998.

Ottersten, H.: Mean vertical gradients of potential refractive index in turbulent mixing and radar detection of CAT, Radio Sci., 4, 1247-1249, 1969.
Rajopadhyaya, D. K., May, P. T., and Vincent, R. A.: The retrieval of ice particle size information from VHF wind profiler Doppler spectra, J. Atmos. Ocean. Tech., 11, 1559-1568, 1994.

Ralph, F. M.: Using radar-measured radial vertical velocities to distinguish Precipitation scattering from Clear-air scattering, J. Atmos. Ocean. Tech., 12, 257-267, 1995.

Rao, T., Rao, D., and S., R.: Tropical precipitating systems observed with Indian MST radar, Radio Sci., 34, 1125-1139, 1999.

Slater, K., Stevens, A. D., Pearman, S. A. M., Eccles, D., Hall, A. J., Bennett, R. G. T., France, L., Roberts, G., Olewicz, Z. K., and Thomas, L.: Overview of the MST radar system at Aberystwyth, in Proceedings of the Fifth workshop on Technical and Scientific Aspects of MST radar, pp. 479-482, SCOSTEP secretariat, University of Illinois, Urbana, 1991.

Vaughan, G.: The UK MST radar, Weather, 57, 69-73, 2002.

Vaughan, G. and Worthington, R. M.: Effects of humidity and precipitation on VHF radar vertical beam echoes, Radio Sci., 35, 1389-1398, 2000.

Wakasugi, K., Mizutani, A., Matsuo, M., Fukao, S., and Kato, S.: A direct method for deriving drop-size distribution and vertical air velocities from VHF Doppler radar spectra, J. Atmos. Ocean. Tech., 3, 623-629, 1986.

Williams, C. R., Ecklund, W. L., and Gage, K. S.: Classification of Precipitating clouds in the Tropics using 915MHz Wind Profilers, J. Atmos. Ocean. Tech., 12, 996-1012, 1995.

Woodman, R. F.: Spectral moment estimation in MST radars, Radio Sci., 20, 1185-1195, 1985. 